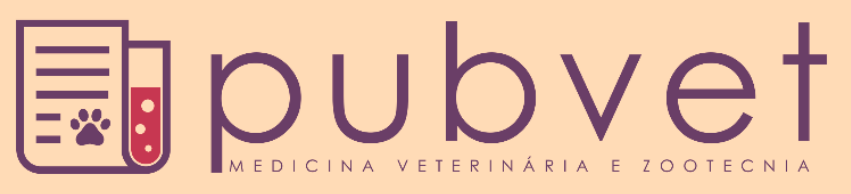

https://doi.org/10.31533/pubvet.v13n01a250.1-19

\title{
Pesquisas com abelhas-sem-ferrão (Hymenoptera: Meliponini) e aplicabilidade dos marcadores moleculares: Uma revisão sistemática da literatura
}

\author{
Geice Ribeiro da Silva ${ }^{*} \bullet$, Fábia de Mello Pereira ${ }^{2} \bullet$, Bruno de Almeida Souza $^{2}$, Maria \\ Teresa do Rêgo Lopes $^{2} \bullet$, Fábio Mendonça Diniz ${ }^{3} \bullet$
}

${ }^{\text {I} D o u t o r ~ p e l a ~ U n i v e r s i d a d e ~ F e d e r a l ~ d o ~ P i a u i ́, ~ P r o g r a m a ~ d e ~ P o ́ s-g r a d u a c ̧ a ̃ o ~ e m ~ C i e ̂ n c i a ~ A n i m a l ~(T e r e s i n a, ~ P i a u i ́ ~-~ B r a s i l) ~}$ ${ }^{2}$ Pesquisador da Empresa Brasileira de Pesquisa Agropecuária - Embrapa Meio-Norte (Teresina, Piauí - Brasil)

${ }^{3}$ Pesquisador da Empresa Brasileira de Pesquisa Agropecuária - Embrapa Caprinos e Ovinos (Sobral, Ceará - Brasil)

*Autor para correspondência, E-mail: geiceamb_bio@yahoo.com.br

Resumo. Distribuídas principalmente nas áreas de clima Tropical e Subtropical Temperado, abelhas-sem-ferrão (tribo Meliponini) se destacam por sua grande diversidade, com variados padrões de morfologia e comportamento. Além de sua importância econômica, são cruciais para a polinização de vegetação selvagem e cultivada. Porém, suas populações estão reduzindo devido à degradação ambiental. Portanto, uma revisão sistemática da literatura foi realizada, por meio de uma busca no banco de dados da Web of Science por estudos voltados à abelhas-sem-ferrão, nos principais países da região Pantropical. Foram avaliadas todas as publicações, porém, com maior ênfase aos estudos voltados à aplicação de marcadores moleculares. Somente $11,25 \%$ do que foi produzido para Apis mellifera foi gerado de publicações com abelhas-sem-ferrão, sendo que os países que mais se destacaram foram o Brasil, Austrália e México. Os marcadores moleculares mais abordados foram os microssatélites de DNA (SSRs) e os marcadores mitocondriais (ex.: 16S rRNA, COI e Cyt-b). Apenas dezessete conjuntos de marcadores específicos foram desenvolvidos e somente dois mitogenomas foram sequenciados até o momento. Adicionalmente, foram selecionados 18 marcadores microssatélites heteroespecíficos que tiveram sucesso em várias espécies e que podem ser úteis para outros estudos genéticos. Pela importância ecológica e econômica, pesquisadores da região Neotropical têm tido maior interesse nas pesquisas com abelhas-sem-ferrão, com destaque para a utilização de marcadores moleculares específicos e heteroespecíficos que têm se mostrado essenciais na tomada de decisão quanto à conservação e manejo dos meliponineos.

Palavras-chave: Estudos genéticos, marcadores heteroespecíficos, microssatélites de DNA, tribo Meliponini.

\section{Research on stingless bees (Hymenoptera: Meliponini) and applicability of molecular markers: A systematic review of the literature}

Abstract. The stingless bees (Meliponini tribe) are distributed in the areas of tropical and
subtropical temperate climate, and stand out among bees for their great diversity with
varied patterns of morphology and behavior. In addition to their economic importance, as
well as economic importante, these bees are crucial in pollination of wild vegetation and
cultivated crops. However, their population size is decreasing due to environmental
degradation. Therefore, a literature review was conducted, in the Web of Science database
focusing on stingless bees, in the main countries of the Pantropical region. We assessed 
publications on stingless bees, in a broad sense, and more specifically those referring to the application of molecular markers on these species. Only $11.25 \%$ of what was produced for Apis mellifera was generated from publications with stingless bees, being Brazil, Australia and Mexico the most prominent countries. The most widely used molecular markers were microsatellite loci and mitochondrial markers (e.g. 16S rRNA, COI and Cyt-b). Only 17 sets of specific markers were developed and two mitogenomas were sequenced. Moreover, 18 heterospecific microsatellite markers have been successful in several species, and therefore, may also be useful for other genetic studies. Due to their ecological and economic importance, researchers in the Neotropical region have been more interested in genetic studies with stingless bees, especially by using specific and heterospecific molecular markers. These tools have also proved to be essential in decision-making for the conservation and management of Meliponini bees.

Keywords: Genetic studies, heterospecific markers, DNA microsatellites, Meliponini tribe

\section{Investigaciones con abejas sin aguijón (Hymenoptera: Meliponini) y aplicabilidad de los marcadores moleculares: Una revisión sistemática de la literatura}

Resumen. Distribuidas principalmente en las áreas de clima tropical y subtropical templado, las abejas sin aguijón (tribus Meliponini) se destacan por su gran diversidad, con variados patrones de morfología y comportamiento. Además de su importancia económica, son cruciales para la polinización de vegetación salvaje y cultivada. Sin embargo, sus poblaciones están reduciendo debido a la degradación ambiental. Por lo tanto, una revisión sistemática de la literatura fue realizada, por medio de una búsqueda en el banco de datos de la Web of Science por estudios dirigidos a las abejas sin aguijón, en los principales países de la región Pantropical. Se evaluaron todas las publicaciones, sin embargo, con mayor énfasis en los estudios orientados a la aplicación de marcadores moleculares. Sólo el $11,25 \%$ de lo que fue producido para Apis mellifera fue generado de publicaciones con abejas sin aguijón, siendo que los países que más se destacaron fueron Brasil, Australia y México. Los marcadores moleculares más abordados fueron los microsatélites de ADN (SSR) y los marcadores mitocondriales (por ejemplo, 16S rRNA, COI y Cyt-b). Sólo diecisiete conjuntos de marcadores específicos fueron desarrollados y sólo dos mitogenomas fueron secuenciados hasta el momento. Adicionalmente, se seleccionaron 18 marcadores microsatélites heteroespecíficos que tuvieron éxito en varias especies y que pueden ser útiles para otros estudios genéticos. Por la importancia ecológica y económica, los investigadores de la región Neotropical han tenido mayor interés en las investigaciones con abejas sin aguijón, con destaque para la utilización de marcadores moleculares específicos y heteroespecíficos que se han mostrado esenciales en la toma de decisión en cuanto a la conservación y manejo de los meliponinos.

Palabras clave: Estudios genéticos, tribu Meliponini, microsatélites de ADN, marcadores heteroespecíficos

\section{Introdução}

Caracterizadas pelo ferrão atrofiado, a tribo Meliponini é o grupo de abelhas com maior diversidade de espécies, com distribuição em praticamente todo o planeta, na faixa territorial que compreende a região Pantropical, principalmente nas áreas de climas Tropicais e Temperado Subtropicais. Nesse perímetro, das 20.000 espécies de abelhas até então registradas, estima-se que existam cerca de 400 espécies de abelhas desse grupo (Silveira et al., 2002; Michener, 2007).

Devido à sua complexidade e diversidade comportamental, bem como abundância e importância como polinizadores de vegetação natural e cultivada, esse grupo de abelhas vem sendo amplamente estudado, com destaque para o Brasil, México e Austrália. Nesses países, no geral, têm havido grande esforço das instituições de pesquisa no incentivo à prática da meliponicultura (atividade de criação 
racional das abelhas-sem-ferrão), com o propósito principal de conservação das espécies (Ferreira et al., 2010). Porém, devido às constantes ações de degradação ambiental, os estoques populacionais tendem a diminuir ameaçando esse importante recurso natural (Cámara et al., 2004; Silva et al., 2014a).

Para que as práticas de conservação das espécies de abelhas-sem-ferrão seja eficiente, a compreensão de alguns temas se tornam essenciais no planejamento das ações, como por exemplo, a morfofisiologia, o comportamento social, os estudos genéticos e a taxonomia das espécies. Tais conhecimentos poderão garantir a formulação de estratégias eficazes de manejo e conservação, de forma a manter e ampliar os estoques populacionais nos meliponários, principalmente durante os períodos do ano onde as condições climáticas são mais adversas.

Devido aos avanços nos campos da estatística, biologia molecular e bioinformática, ferramentas avançadas vêm sendo desenvolvidas e disponibilizadas no meio científico, o que possibilita maior confiabilidade dos estudos genéticos, principalmente no que se refere à utilização de marcadores moleculares. Com as informações geradas é possível esclarecer várias lacunas que apenas pelos métodos tradicionais seria difícil solucionar como, por exemplo, questões que envolvem estudos ligados ao comportamento migratório, reprodutivo e taxonômico das espécies.

Diante do exposto, com adoção de ferramentas de busca e análise de base de dados consolidadas, objetivou-se com essa revisão de literatura fornecer uma visão geral das principais tendências nos estudos com abelhas-sem-ferrão com enfoque na aplicação de marcadores moleculares.

\section{Metodologia}

Foi executada uma revisão de literatura, no qual foram levantados registros de publicações de abelhas-sem-ferrão envolvendo estudos gerais e com foco em marcadores moleculares, principalmente microssatélites e mitocondriais.

O levantamento reuniu estudos de pesquisadores dos países da faixa Pantropical, onde está distribuída a maior parte das abelhas-sem-ferrão (tribo Meliponini), conforme sugerido por Michener (2007). Como critério adotado para a pesquisa, todos os autores foram retirados da plataforma de pesquisa Web of Science (WOS) da Clarivate Analytics (anteriormente ISI Web of Knowledge), atualmente a principal plataforma de pesquisa em informação nas Ciências Naturais, Ciências Sociais, Artes e Humanidades, que lista os endereços completos dos autores e coautores de cada publicação. Na WOS, as consultas foram feitas na "pesquisa avançada", direcionada a palavras indexadas contidas no título, palavras-chave e resumo de registros datados de todos os anos até 31 de Abril de 2018. Com uso dessa opção adotou-se uma sequência chave com seguintes argumentos, separadamente: TS = (stingless bee $\left.^{*}\right), \mathrm{TS}=($ stingless bee* AND microsatellite $*), \mathrm{TS}=$ (stingless bee* AND mitochondrial $*$ ). A sigla TS é o identificador que permite a busca no WOS de palavras que estão inseridas no título, palavraschave e abstract.

Além dos marcadores microssatélites e mitocondriais foram pesquisados outros marcadores, aqueles mais utilizados em estudos de caracterização molecular e populacionais: ISSR (Inter simple Sequence Repeats - Entre repetições de sequências simples), AFLP (Amplified Fragment Length Polymorphism - Polimorfismo de comprimento de fragmentos amplificados), RFLP (Restriction Fragment Length Polymorphism - Polimorfismo de comprimento de fragmentos restringidos), RAPD (Random Amplified Polymorphism DNA - Polimorfismo de DNA amplificado aleatoriamente) e ITS (Internal Transcribed Spacer - Espaçador transcrito interno). Os rótulos de campo e operadores booleanos foram os mesmos utilizados anteriormente, substituindo na pesquisa as palavras "microsatellite*" ou "mitochondrial*" pelos respectivos marcadores. Posteriormente, foram adotados os mesmos argumentos, porém direcionados aos países onde as abelhas-sem-ferrão estão distribuídas, conforme o seguinte exemplo: $\mathrm{TS}=($ stingless bee $*$ AND microsatellite*) AND CU $=$ Brazil, no qual a sigla CU é o identificador do WOS que refere-se a país. Os países empregados na pesquisa foram: da região Neotropical - Brasil, México, Venezuela, Panamá, Guatemala, Equador, Colômbia, Argentina e Costa Rica; Sudoeste da Ásia - Tailândia, Vietnã, Índia, Indonésia, Filipinas e Malásia; África - Uganda, Quênia, Gabon, Gana e África do Sul e por último a Austrália.

Ao tomar como foco os marcadores moleculares, baseado na metodologia sugerida por Moura et al. (2017), buscou-se enfatizar o endereço fornecido pela instituição do primeiro autor, dentro dos países 
incluídos na abordagem. As demais pesquisas foram adotadas conforme padronizado pela plataforma de pesquisa. Caso o endereço do primeiro autor não estivesse incluído, optou-se pelo endereço do segundo autor. No caso de o autor apresentar endereços múltiplos foi escolhido o endereço que estivesse dentro da abordagem.

A fim de se realizar a análise, em "registros completos" os resultados foram salvos em arquivos formato "txt" conforme recursos do próprio site de pesquisa WOS. Os resultados das pesquisas foram submetidos ao software de pesquisas bibliométricas Bibexcel (Persson et al., 2009). Com o auxílio do programa "Excel" da Microsoft, a partir dos dados gerados do software Bibexcel foi possível filtrar apenas os estudos realizados por pesquisadores referentes aos países em avaliação, conforme o critério citado acima.

Em relação aos marcadores microssatélites e mitocondriais foram verificados, individualmente em cada trabalho, as espécies de maior interesse que empregaram cada um dos marcadores.

Para uma avaliação geral do estudo que envolve abelhas-sem-ferrão, a critério dos autores, foi verificado a frequência das palavras-chave referente aos temas: morfofisiologia, produção, polinização, comportamento, reprodução, taxonomia, conservação e estudos genéticos. De forma a verificar a aplicabilidade do uso dos marcadores microssatélites em abelhas-sem-ferrão, verificou-se também a frequência das palavras-chave referente aos temas: população, reprodução, conservação e comportamento.

Por fim, providenciou-se uma lista de marcadores microssatélites heteroespecíficos mais polimórficos até então desenvolvidos que foram úteis para diversas espécies, de forma que possa contribuir em estudos futuros, a fim de servir como guia para grupos de pesquisa voltados à conservação e manutenção das espécies de abelhas-sem-ferrão.

\section{Pesquisas no mundo}

Distribuídos principalmente entre notas científicas, estudos de revisão e artigos científicos, foram registrados 1.195 trabalhos produzidos por autores principais (APs) exclusivamente oriundos das instituições presentes nos países das regiões Pantropicais, com a maioria dos trabalhos gerados por pesquisadores residentes em instituições da América do Sul, América Central e Austrália (Figura 1).

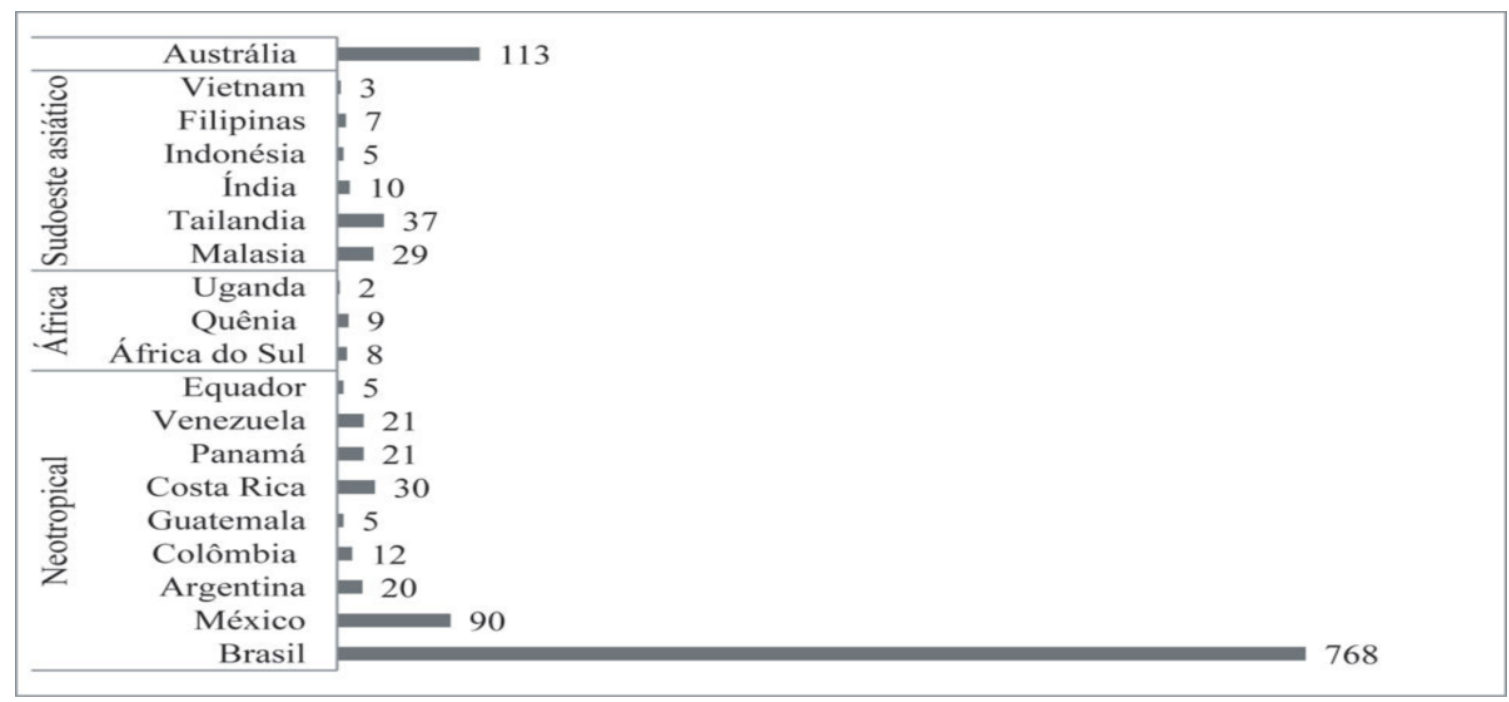

Figura 1. Número de publicações depositadas no Web of Science por autores principais (APs) dos países onde as abelhas-sem-ferrão estão distribuídas geograficamente.

No mundo os autores brasileiros foram os que tiveram maior destaque em número de publicações com abelhas-sem-ferrão. Em uma abordagem geral, o país teve quase sete vezes mais publicações do que o segundo colocado (Austrália). Além do Brasil, na América do Sul, poucos estudos, foram registrados, sendo que a Venezuela foi o segundo país mais produtivo, com registros de 21 publicações no total. Outros como Chile, Peru, e Bolívia não registraram trabalhos científicos, o que mostra a 
necessidade de mais pesquisas, já que há grande biodiversidade de abelhas nativas, com perspectiva de haver muitas espécies ainda não catalogadas nesses países.

Provavelmente, o baixo volume de estudos de abelhas-sem-ferrão tenha justificativa no fato de as espécies desse grupo não serem atrativos ao mercado, uma vez que o nível de produção do seu principal produto, o mel, é inferior, ao das abelhas da espécie Apis mellifera que é entorno de 50 litros/colônia/ano (Gonçalves et al., 2010). A produção de abelhas-sem-ferrão abrange cerca de 0,5 a 1,5 litros/ano em abelhas de pequeno porte, como a jataí (Tetragonisca angustula), e de 4 a 6 litros/ano em abelhas de grande porte como a tiúba (Melipona fasciculata) (Nogueira-neto, 1997; Venturieri, 2008), podendo chegar a 13 litros/ano em meliponários na Baixada Maranhense em condições de boa florada (informações de criadores). A produção de mel em abelhas-sem-ferrão é praticamente relegada aos mercados locais ou mesmo à agricultura familiar (Cámara et al., 2004). Uma pesquisa rápida realizada no banco de dados da WOS confirma o maior interesse dos pesquisadores com as abelhas melíferas, com 14.431 publicações, superior, portanto, ao de abelhas-sem-ferrão, sobre o qual foram registradas apenas 1.623 publicações no total.

No geral, ao reunir por temas as palavras-chave dos três países que mais publicaram no mundo (Brasil, México e Austrália), os pontos mais explorados foram: comportamento, morfofisiologia e estudos genéticos. No que se referem à temática estudos genéticos, pesquisadores dos três países continuaram tendo maior destaque, principalmente quando ligado à utilização de marcadores moleculares em abelhas-sem-ferrão. Isso demonstra a preocupação por parte desses pesquisadores pela caracterização e entendimento das espécies desse grupo, já que a criação racional pode ser dificultada pelo padrão diferenciado de comportamento, o que exige formas de criação específicas.

\section{Pesquisas na região Neotropical}

Na região Neotropical, que abrange países da América Central e do Sul, no geral, houve maior número de publicações referentes as abelhas-sem-ferrão. O país que mais publicou foi o Brasil, com aproximadamente $79 \%$ dos trabalhos, seguido do México (9\%) e Costa Rica (3\%) (ver Figura 1). O Brasil se destacou em estudos mais voltados ao aspecto comportamental com 321 (26\%) palavras-chave das relacionadas, seguido por estudos genéticos e morfofisiológicos, com 292 (24\%) e 241 (20\%), respectivamente (Figura 2).

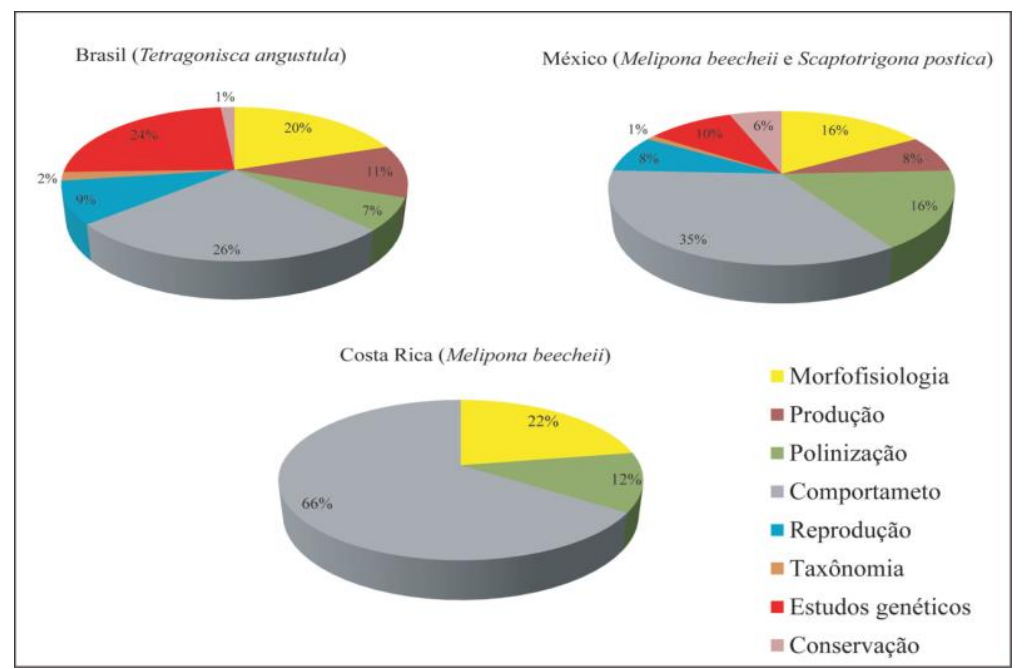

Figura 2. Percentual de palavras-chave referente aos principais temas abordados e à espécie mais citada em estudos com abelhas-sem-ferrão no Brasil, México e Costa Rica.

No Brasil, ao ser analisado isoladamente o número de estudos publicados pelo primeiro ou segundo autor em cada espécie das treze mais citadas nas palavras-chave [Exemplo: TS= ("Melipona quadrifasciata") AND CU=Brazil], a Melipona quadrifasciata foi a primeira colocada com 116 publicações, seguida pela $T$. angustula e $M$. scutellaris, com 72 e 59, respectivamente (Figura 3). Apesar de na espécie T. angustula ter havido maior interesse por estudos voltados à produção de mel e própolis, principalmente devido ao aspecto medicinal comprovado dos produtos (Borsato et al., 2013), nessas 
espécies houve grande preocupação com os temas ligados à morfofisiologia, comportamento e estudos genéticos.

Com o que foi exposto, verificou-se uma preocupação dos pesquisadores referente à busca de maior conhecimento por essas espécies, porém sabe-se que essas abelhas têm grande potencial econômico, atribuído não só a seus produtos (mel e própolis) (Mercês et al., 2013; Santos et al., 2017), como também ao serviço de polinização, tanto de plantas nativas como também de cultivadas, como os tomateiros (nome cientifico Lycopersicon esculentum, polinizado por M. quadrifasciata) e cenouras (Daucus carota - T. angustula) (Nascimento et al., 2012, Bartelli \& Nogueira-Ferreira, 2014). Isso reflete no crescente número de artigos científicos voltados aos estudos genéticos, uma vez que para haver adaptação às regiões onde estão localizadas, principalmente frente às constantes mudanças ambientais, uma gama de modificações genéticas importantes deve está em processo, o que caracteriza as populações de abelhas de tal forma que sejam necessárias estratégias de manejo diferenciadas para a sua criação.

Além das implicações genéticas, esses tipos de estudos, tendem a esclarecer cada vez mais aspectos como o padrão comportamental e reprodutivo das espécies, de forma a direcionar métodos mais eficazes de manejo e conservação, uma vez que é notório a dependência do forrageamento das abelhas com as condições de temperatura e umidade, podendo ser alterado com as mudanças no aquecimento global (Silva et al., 2011; Giannini et al., 2012).

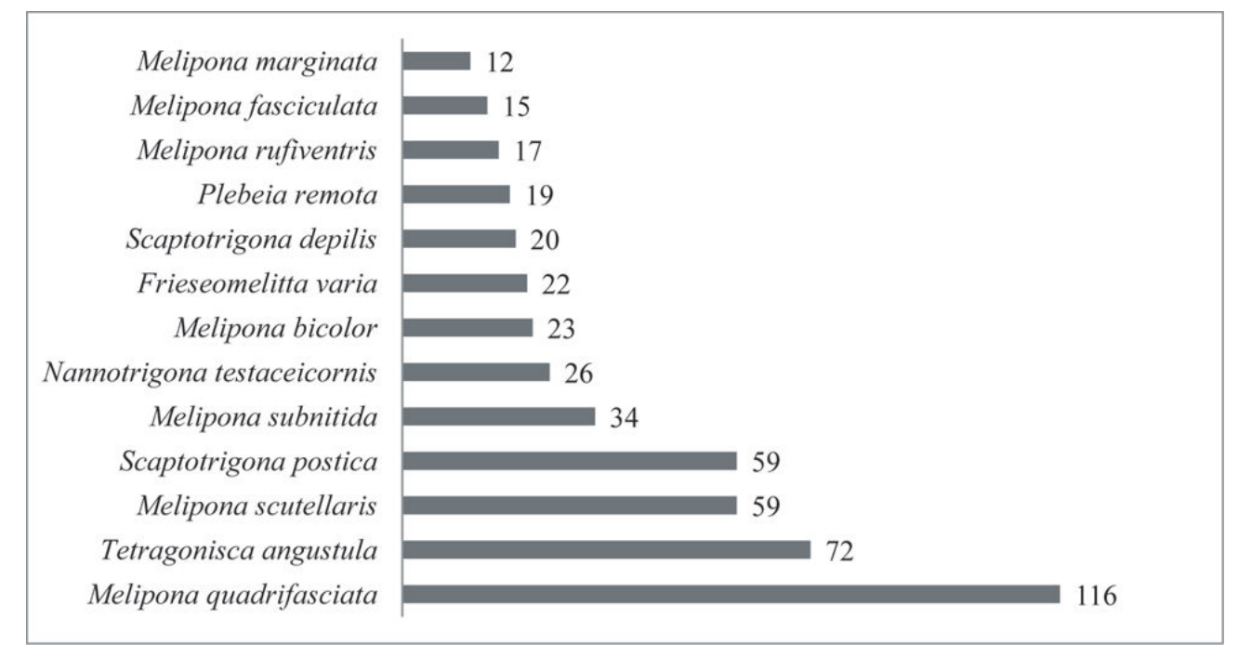

Figura 3. Número de publicações geradas por autores brasileiros ao realizar a pesquisa de cada espécie das 13 mais citadas nas palavras-chave obtidas de todos os resgistros reunidos do Web of Science [TS=("espécie") AND CU = Brazil].

Com pelo menos 46 espécies catalogadas no país (Ayala, 1999), o México foi o terceiro colocado em publicações científicas no mundo e o segundo na região Neotropical, tendo a temática, comportamento, como maior destaque. Porém, a polinização e a morfofisiologia, também foram temas bastante discutidos (ver Figura 2). O interesse dos pesquisadores pela polinização, talvez possa ser explicado pelo fato de o país ter destaque dentre aqueles da América Latina, na produção de produtos agrícolas orgânicos (Luizzi et al., 2016). Sabe-se que a produção de cultivares associadas com a criação de abelhas pode aumentar não só a quantidade de sementes como a qualidade dos frutos. Porém, apenas a Apis mellifera e Bombus impatiens estão comercialmente disponíveis no país na prestação de serviços de polinização, tanto por meio do aluguel como venda de colmeias para agricultores (Torres-Ruiz et al., 2013).

Talvez esse tenha sido um dos prováveis fatores que incentivaram pesquisas com abelhas nativas no México nos mais diferentes aspectos, especialmente no que tange às espécies Melipona beecheii (8), Scaptotrigona mexicana (8) e Melipona colimana (5). Estudos têm demonstrado, por exemplo, que $S$. mexicana são excelentes na polinização de cultivares como abacate [Persea americana (Lauraceae)], rambutan [Nephelium lappaceum (Sapindaceae)], e café [Coffea arabica (Rubiaceae)] (Ayala et al., 2013). 
Já a Costa Rica gerou, por parte dos APs, quantidade mais pronunciada de estudos voltados à abelha M. beecheii, seguido por Tetragonisca angustula e Trigona corvina, com 11, 9 e 9 publicações, respectivamente (ver Figura 2).

$\mathrm{Na}$ Argentina houve preferência nos estudos pelas espécies $M$. quadrifasciata e Tetragonisca fiebrigi, com três publicações cada. Na Guatemala, por sua vez, o maior interesse foi pelas abelhas Melipona yucatanica e M. beecheii, com duas publicações para cada espécie. Na Colômbia as abelhas Melipona eburnea, Trigona nigra e Tetragonisca angustula foram as mais pesquisadas, com apenas duas publicações de cada espécie. E no Panamá, as abelhas T. angustula, Melipona panamica, Lestrimellita limao e Trigona hypogea foram as que tiveram mais destaque, com duas publicações cada. No Equador e Venezuela não houve estudos direcionados especificamente a uma espécie havendo predominância de estudos exploratórios.

Países como Uruguai, Cuba e El-Salvador ocorreram apenas duas produções científicas, sem preferência por determinada espécie. Nos demais países da região Neotropical nenhum registro de publicações com abelhas-sem-ferrão foi observado.

Com exceção de Brasil e México, no geral nesses outros países da região Neotropical, o aspecto comportamental e produtivo foram os principais temas abordados, com poucos estudos genéticos voltados a marcadores moleculares (ver Tabela 1). Com esses resultados mostra-se, no geral maior interesse dos pesquisadores voltado a temáticas ligadas ao aspecto econômico, uma vez que é notório os benefícios da meliponicultura, principalmente no que se refere à economia de subsistência em países subdesenvolvidos (Gemim et al., 2017).

Tabela 1. Número de publicações depositadas no Web of Science pelo primeiro ou segundo autores (APs - Autores Principais) lotados nas instituições oriundas das regiões onde as abelhas-sem-ferrão estão distribuídas que utilizaram marcadores moleculares em estudos genéticos

\begin{tabular}{lcccccccc}
\hline Países & Microssatélites & $m t$ DNA & ISSR & ITS1/ITS2 & AFLP & RFLP & RAPD & Total \\
\hline Brasil & 54 & 32 & 6 & 2 & 2 & 13 & 6 & 115 \\
México & 7 & 8 & 0 & 6 & 0 & 2 & 0 & 23 \\
Colômbia & 0 & 1 & 0 & 0 & 0 & 0 & 0 & 1 \\
Guatemala & 1 & 1 & 0 & 0 & 0 & 0 & 0 & 2 \\
Equador & 0 & 2 & 0 & 0 & 0 & 0 & 0 & 2 \\
África do Sul & 0 & 1 & 0 & 0 & 0 & 0 & 0 & 1 \\
Quênia & 0 & 1 & 0 & 0 & 0 & 0 & 0 & 1 \\
Malásia & 0 & 1 & 0 & 0 & 0 & 0 & 0 & 1 \\
Tailândia & 0 & 2 & 0 & 0 & 3 & 0 & 0 & 5 \\
Austrália & 10 & 5 & 0 & 0 & 0 & 0 & 0 & 15 \\
\hline Total & 72 & 54 & 6 & 8 & 5 & 15 & 6 &
\end{tabular}

mtDNA, DNA mitocrondrial; ISSR, Entre sequencias simples repetidas (Inter Simple Sequence Repeat); ITS, Espaçador Interno Transcrito (Internal Transcribed Spacer); AFLP, Polimorfismo no comprimento dos fragmentos amplificados (Amplified Fragment Length Polymorphism); RFLP, Polimorfismo no comprimento dos fragmentos restringidos (Restriction Fragment Length Polymorphism) e RAPD, Polimorfismo de DNA aleatoriamente amplificado (Random Amplified Polymorphism DNA).

Do ponto de vista do uso de marcadores moleculares, dos dez países do mundo que tiveram estudos publicados por APs, na região Neotropical, Brasil e México foram os que mais se destacaram em publicações, sendo os mais utilizados, os marcadores microssatélites (72 publicações) e os de origem mitocondrial (54 publicações) (Tabela 1).

Além dos marcadores microssatélites terem sido os mais utilizados no Brasil, dos 17 conjuntos de marcadores específicos disponíveis no período abordado, a maioria foi desenvolvido por APs brasileiros, com exceção daqueles gerados por Peters et al. (1998) (Melipona bicolor), Paxton et al. (1999) (Scaptotrigona postica) e Green et al. (2001) (Trigona carbonaria). Nove foram para abelhas do gênero Melipona, sendo elas: Melipona seminigra, M. interrupta manaosensis, M. mondury, M. bicolor, $M$. quadrifasciata, $M$. capixaba, $M$. scutellaris, $M$. rufiventris e $M$. subnitida, provavelmente pela importância e grande diversidade de espécies do gênero presentes no país (Tabela 2). 
As quatro espécies brasileiras que mais apareceram com estudos utilizando esses marcadores, foram: Tetragonisca angustula (7), M. scutellaris (7), M. mondury (5) e M. quadrifasciata (5). A maior parte dos estudos estava voltada para a caracterização populacional, com 25 palavras-chave ligadas ao tema. Em seguida, os aspectos referentes à reprodução, conservação e comportamento foram os mais citados, com $17 \%$ das citações cada (Figura 4). Isso reforça a preocupação dos pesquisadores por esse tipo de abelha, pois em consequência das constantes mudanças ambientais causadas pela expansão industrial e agrícola sabe-se que os primeiros sinais de ameaça refletem principalmente em alterações no padrão comportamental e reprodutivo das colônias, sendo que uma avaliação genética associada a esses marcadores se torna oportuna.

Tabela 2. Relação de abelhas-sem-ferrão que possuem marcadores moleculares microssatélites desenvolvidos para espécie com a indicação da referência e o método empregado para seu desenvolvimento.

\begin{tabular}{llc}
\hline Espécie & Referência & Método \\
\hline Melipona subnitida & Souza et al. (2014) & NGS \\
Trigona spinipes & Santiago et al. (2015) e Jaffé et al. (2016) & NGS \\
Scaura latitarsis & Franscisco et al. (2013) & Tradicional \\
Scaptotrigona xanthotricha & Duarte et al. (2012) & Tradicional \\
Plebeia remota & Francisco et al. (2011) & Tradicional \\
$M$. interrupta manaosensis & Francini et al. (2010) & Tradicional \\
M. mondury & Lopes et al. (2010) & Tradicional \\
Nannotrigona testaceicornis & Oliveira et al. (2009) & Tradicional \\
Tetragonisca angustula & Brito et al. (2009) & Tradicional \\
M. seminigra merrilae & Francini et al. (2009) & Tradicional \\
$M$. rufiventris & Lopes et al. (2009) & Amplificação ISSR \\
M. bicolor & Peters et al. (1998) & Tradicional \\
$M$. quadrifasciata & Tavares et al. (2013a) & Tradicional \\
$M$. capixaba & Nogueira et al. (2014) & Amplificação ISSR \\
M.scutellaris & Tavares et al. (2013b) & Tradicional \\
Scaptotrigona postiça & Paxton et al. (1999) & Tradicional \\
Trigona carbonária & Green et al. (2001) & Tradicional \\
\hline
\end{tabular}

NGS, Sequenciamento de Nova Geração; Tradicional, Método que emprega a clonagem molecular para o desenvolvimento e isolamento de microssatélites; Amplificação ISSR, Método que emprega como base os fragmentos amplificados por primers ISSR para a obtenção dos microssatélites.

No México, utilizando os marcadores microssatélites, a espécie mais estudada foi a Scaptotrigona mexicana, sendo que a maior tendência foi a aplicação desse marcador em estudos de caracterização populacional (50\% das palavras-chave relacionadas), comportamental (38\% das palavras-chave) e referente à conservação (12\%) (Figura 4).

Dentro do que foi avaliado, o Brasil foi o único país que desenvolveu estudos com marcadores ISSR e RAPD. Apesar da facilidade metodológica e baixo custo, esses tipos de marcadores possuem limitações quanto aos resultados fornecidos, pois pelo fato de serem do tipo dominante, fornecem poucas informações biológicas, quando comparado com aqueles do tipo codominante (ex.: microssatélites e RFLP). Isso se agrava ainda mais para o marcador RAPD devido à baixa taxa de reprodutividade $\mathrm{e}$ repetibilidade nas reações (Yang et al., 2013) (Tabela 1), o que reflete as restrições levantadas por alguns periódicos quanto à sua utilização em artigos científicos.

Apesar disso, além de auxiliar outros marcadores, o uso de marcadores dominantes pode ser ideal para o início dos estudos, pois pode indicar que direção seguir nas pesquisas. A partir de estudos preliminares, por meio deles pode-se ter uma ideia do nível de diferenciação entre as populações (Silva et al., 2014b). Além disso, junto a outros marcadores, podem contribuir significativamente na construção e adensamento dos mapas genéticos úteis para o melhoramento genético.

O Brasil teve, ainda, o maior volume de estudos utilizando marcadores RFLPs em abelhas-semferrão, com 13 publicações. A principal utilização foi na avaliação de sequências de DNA de genes mitocondriais e ITS, sendo uma alternativa ao uso de sequenciadores (ver Tabela1) (Nogueira et al., 
2014). A técnica se baseia na utilização de enzimas de restrição, que geram uma matriz de dados de frequências alélicas, típicas de marcadores codominantes, fornecidas a partir de mutações ou não dos sítios de ligação da enzima, em regiões-alvo dos genes anteriormente amplificados por PCR. Essa estratégia reflete, ainda, uma falta de estrutura em várias instituições de pesquisa brasileiras quanto a equipamentos mais avançados como sequenciadores, sendo em sua maioria sanada por meio de parcerias mantidas com instituições de países desenvolvidos.

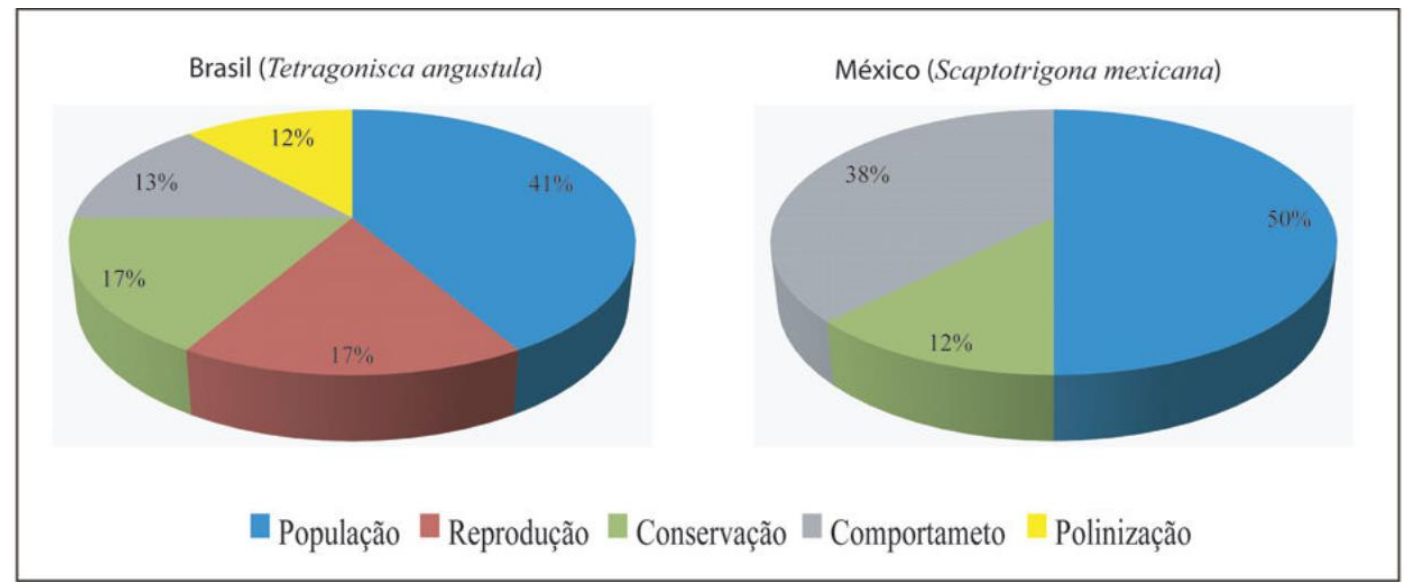

Figura 4. Temas mais discutidos no Brasil e México com abelhas-sem-ferrão e a espécie mais estudada empregando marcadores microssatélites.

O Brasil e o México foram os únicos que apresentaram estudos com marcadores ITS. É um marcador importante para análises filogenéticas de táxons próximos, demonstrando eficiência em abelha-semferrão, tanto em análise do nível intra como interespecífico devido à rápida taxa evolutiva, como observado para as espécies M. quinquefasciata e M. subnitida (Cruz et al., 2006; Pereira et al., 2009). É um marcador neutro que faz parte do locus DNA ribossômico nuclear eucariótico que separa internamente duas regiões funcionais. Os mais utilizados em abelhas-sem-ferrão são o ITS1 (Nogueira et al., 2014) e ITS2 (Rúa et al., 2007). O primeiro é uma região interna que separa os genes 18S rDNA e 5,8S rDNA e o segundo entre o 5,8S rDNA e $28 \mathrm{~S}$ rDNA.

Quanto aos estudos utilizando os marcadores de origem mitocondrial, o Brasil teve grande desempenho em publicações, tanto em relação à região Neotropical como no mundo. As abelhas $M$. quadrifasciata (6), T. angustula (4) e M. rufiventris (4) foram as mais estudadas. No caso do México as publicações dos APs abordaram com maior frequência as pesquisas com a espécie Scaptotrigona hellwegeri.

No geral, os marcadores mitocondriais mais utilizados em abelhas-sem-ferrão compreende parte das sequências dos genes 16S (região que transcreve o RNA da subunidade maior ou 16S do RNA ribossomal), Cox-I (gene que codifica o citocromo oxidase) e Cyt-b (gene que codifica o citocromo b), sendo comumente utilizados em estudos de filogenia e de sistemática. O principal motivo desses genes serem comumente utilizados em filogenia se deve ao fato de suas sequências serem semiconservadas evolutivamente; serem genes de cópia única, adequadas ao alinhamento de sequências; terem taxa de substituição informativa que refletem com mais efetividade a distinção entre as espécies; e pôr os eventos de recombinação genética serem raros para a maioria dos genes, o que possibilita que as variações observadas sejam oriundas apenas de mutações evolutivas ocorridas por substituição, deleção ou inserção de nucleotídeos (Patwardhan et al., 2014).

A principal técnica empregada para sua avaliação em estudos populacionais com abelhas-sem-ferrão foi o sequenciamento, apesar de alguns estudos terem adotado técnicas mais simples como PCR + RFLP e SSCP (Polimorfismo na Conformação de Fita Simples) no processo de identificação das mutações (Nogueira et al., 2014; Souza \& Carvalho-Zilse, 2014; Santos et al., 2015).

Provavelmente a necessidade de maior conhecimento das espécies, bem como maior esclarecimento taxonômico tenha justificado o volume de estudos que empregam esses tipos de marcadores em abelhassem-ferrão no Brasil. Isso se deve a imensidão de espécies de abelhas presente no país, bem como pela 
consequente diversidade de características morfológicas que vêm a confundir, em alguns casos, no processo de distinção de táxon por parte dos pesquisadores (Gonzalez et al., 2013).

Talvez isso se explique pelo fato dos dados fornecidos pelas características morfológicas, ainda serem bastante limitados em número, sendo em consequência, algumas vezes, a ordem dos táxons alteradas devido à subjetividade da avaliação, o que causa certa confusão quando se precisam estabelecer estratégias de manejo e conservação adequadas a determinadas espécies. Dessa forma, o uso de marcadores moleculares mitocondriais torna-se essencial, pois os dados fornecidos pelos marcadores moleculares são abrangentes em número e formas, uma vez que cada posição nucleotídica pode ser encarada como características independentes, além de sua interpretação ser mais fácil (Patwardhan et al., 2014).

\section{Pesquisas na África}

Poucos estudos foram registrados na WOS por pesquisadores africanos, sendo o continente com o menor número de publicações depositadas. Os países que se destacaram foram o Quênia e a África do Sul com nove e oito registros de APs, respectivamente. Os outros países possuem registros de até três publicações. Muito dos estudos recentes estão voltados ao levantamento faunístico das abelhas na região (Kiatoko et al., 2017; Krausa et al., 2017), sendo, no geral, o aspecto comportamental e relacionado aos produtos gerados os mais explorados pelos pesquisadores. A polinização tem sido outro aspecto, também bastante discutido nas pesquisas.

Houve a produção de um estudo em 1976 e três na década de 80, com foco nas espécies Trigona denoiti e T. gribodoi (Hypotrigona gribodoi). Posteriormente os estudos só vieram a ser registrados no WOS no ano de 2006 (Crewe \& Fletcher, 1976; Keeping et al. 1982; Moritz \& Crewe 1988; Korte et al. 1988). Foram detectados dois registros por parte dos autores africanos de estudos voltados ao emprego de marcadores moleculares, especificamente os de origem mitocondrial, nos países da África do Sul e Quênia (ver Tabela 1).

Vários fatores podem ter influenciado o baixo índice de publicações, dentre eles pode-se destacar: a) desinteresse devido ao baixo nível de produção característicos das abelhas-sem-ferrão; b) Falta de estímulos políticos para a pesquisa e criação racional das abelhas-sem-ferrão que mostrem os benefícios econômicos e ecológicos que poderão ser gerados; e c) devido à incidência de conflitos civis na região que dificultam a pretensão de pesquisas. Apesar disso, em parceria com pesquisadores africanos, foi detectado a participação de países estrangeiros, principalmente da Europa e Austrália liderando pesquisas nessas regiões.

Estimulados pela FAO (Food and Agricuture Organization of the United Nation), no continente africano, alguns estudos têm sinalizado algum interesse em relação ao serviço de polinização, porém, a maior parte das pesquisas está voltada para abelhas melíferas (genêro Apis) (Egoh et al., 2012; GemmillHerren et al., 2014; Melin et al., 2014). Assim, em parceria com outros países, além de mais estudos exploratórios de catalogação nas diferentes regiões do continente, talvez o caminho seja o desenvolvimento de pesquisas direcionadas a cada uma das espécies de abelhas-sem-ferrão, já identificadas, de forma a verificar aquelas que tenham maior potencial não só para a produção, como para o serviço de polinização de cultivares, garantindo maior estimulo e renda adicional para famílias locais que vivem da agricultura de subsistência. Porém, é importante maior incentivo por parte de instituições públicas e/ou organizações não governamentais, não só para as pesquisas, como para a prática da meliponicultura, de forma a inserir os pequenos criadores nesse campo de mercado, já que é uma atividade que não exige altos custos.

\section{Pesquisas no Sudoeste da Ásia}

No sudoeste da Ásia, a Tailândia e Malásia foram os países que se destacaram nos estudos com abelhas-sem-ferrão, sendo 37 e 29 publicações, respectivamente. As espécies mais estudadas nesses dois países foram a Tetragonula laeviceps e Geniotrigona thoracica, respectivamente. Na Índia e Indonésia as abelhas mais investigadas foram as abelhas Tetragonula iripidensis e Trigona minagkabau, respectivamente. Nos outros países do sudoeste asiático, onde houve indexação de publicações científicas, não foram detectados estudos focados em espécies. Nas Filipinas as únicas espécies 
abordadas foram Tetragonula biroi, Trigona sapiens e T. fuscobalteata, e no Vietnam Trigona minor, Lepidotrigona ventralis e Lisiotrigona carpenteri.

No geral, em todos os países asiáticos que estudam abelhas-sem-ferrão, as palavras-chave dão indícios de que os temas mais abordados referem-se à produção de mel, própolis e cerúmen, com destaque para os estudos fisicoquímicos e aqueles referentes à suas propriedades terapêuticas. Na Ásia podem-se destacar os estudos realizados por Nugitrangson et al. (2016) com Tetragonula laeviceps, Jie$\mathrm{Ng}$ (2017) com Trigona sp. e Kustiawan et al. (2017) com Trigona incisa que revelaram o potencial terapêutico dos compostos da própolis, cerumen e mel. Mesmo que essas pesquisas sejam limitadas por ensaios in vitro, elas dão o direcionamento para que estudos futuros, mais completos sejam feitos de forma a agregar valor ao mel, estimulando a criação local e por consequência, a conservação desse importante recurso natural.

Os estudos genéticos, também foram bastante abordados, com poucos realizados por APs associados à região do continente em questão, porém, detectou-se a participação em diversas pesquisas lideradas por outros países, principalmente EUA e Japão.

Dos poucos estudos realizados por APs do continente, a Tailândia foi a que teve maior destaque em estudos utilizando marcadores moleculares. Dentre eles, os mais abordados foram os marcadores AFLP (3 publicações), que se caracterizam pela combinação das técnicas que usam enzimas de restrição e PCR. É um tipo de marcador dominante, que visualizado em gel, fornece uma matriz de dados binários, surgidos em função de mutações nas regiões flanqueadoras (Thummajitsakul et al., 2010). É uma metodologia que além do alto custo e laboriosidade, possui algumas limitações, característico dos marcadores dominantes, porém, por a técnica gerar uma grande quantidade de loci amplificados, são essenciais na construção de mapas genéticos e identificação de QTLs (Quantitative Traits Loci) podendo auxiliar no processo de manejo por meio da seleção assistida por marcadores.

\section{Pesquisas na Austrália}

A Austrália é o segundo maior país do mundo em pesquisas com abelhas-sem-ferrão, sendo associadas principalmente aos temas ligados ao comportamento e a estudos genéticos, superando sozinho o Sudoeste Asiático e o continente africano.

Apesar de serem estimadas cerca de dez espécies de abelhas-sem-ferrão australianas, distribuídas entre os gêneros Trigona e Austroplebeia (Megan et al., 2013), as palavras-chave, apontam até o momento, que os estudos se concentram em apenas duas espécies: Trigona carbonaria e Austroplebeia australis (ver Figura 5).

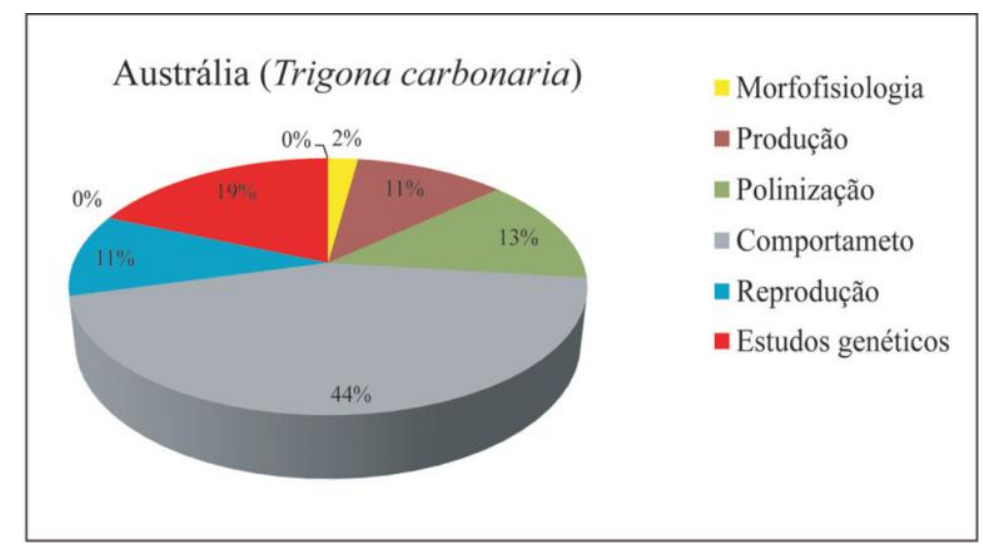

Figura 5. Ocorrências das palavras-chave referentes aos principais temas abordados em estudos com abelhas-sem-ferrão na Austrália.

A polinização é um tema recorrente em muitos estudos, sendo classificado como o terceiro mais discutido. Ao fazer uma busca por sites de instituições relacionadas a serviços de polinização, no portal de pesquisas "Google" observou-se que muitas iniciativas vêm acontecendo no país, tanto por parte de instituições governamentais como por ONGs, com o objetivo principal de conscientizar, incentivar e 
capacitar interessados nesse campo de mercado, prevendo-se, inclusive, ganhos na economia (Monck et al., 2008).

Mesmo as abelhas Apis mellifera sendo as únicas espécies utilizadas nesse tipo de atividade no país, em relação aos EUA, poucos criadores australianos se engajaram nessa atividade. No geral ao se fazer uma pesquisa rápida na WOS (TS = "pollination service"), de um total de 819 publicações, o país com maior interesse em estudos relacionados ao serviço de polinização é o EUA (290), seguido pela Alemanha (137), Inglaterra (136), Brasil (64) e Austrália (59). Ao se refinar a pesquisa para "stingless bee*" o número de publicações mundiais cai para 20 apenas, com destaque para Brasil (10), EUA (6), Alemanha (5), Austrália (3) e Inglaterra (2).

Devido aos estudos realizados principalmente no Brasil, mostrarem a eficiência das abelhas-semferrão na polinização de cultivares (Slaa et al., 2006; Bartelli et al., 2014), algumas instituições como a Aussie Bee \& Australian Native Bee Research Centre (http://www.aussiebee.com.au) têm incentivado o uso das espécies nativas australianas para esse fim, principalmente por serem de fácil criação e prestarem grande serviço ao ecossistema. Porém, para que essa iniciativa atinja o mesmo patamar das abelhas melíferas, há a necessidade de mais estudos de forma a ampliar o conhecimento das espécies nativas. Apesar disso, apenas duas pesquisas estão diretamente ligadas à polinização, relacionados especificamente aos benefícios das abelhas T. carbonaria na polinização de flores de Macadâmia (Heard, 1994; Heard \& Exley, 1994).

De uma forma geral, talvez as iniciativas de instituições governamentais voltadas ao mercado de serviço de polinização tenha sido o fator impulsionador nas pesquisas com abelhas-sem-ferrão, principalmente no que tange ao aspecto comportamental e genético, uma vez que, dentre outros fatores, são fundamentais para melhor entendimento das espécies.

A Austrália foi o terceiro país do mundo em publicações utilizando marcadores moleculares, com registro de estudos apenas com os marcadores microssatélites e mitocondriais.

Assim como para o Brasil e México, os marcadores microssatélites foram os mais utilizados nas pesquisas, nos quais verificou-se associação com temas ligados à caracterização populacional (55\% das palavras-chave relacionadas) e à reprodução (45\% das palavras-chave relacionadas), sendo a espécie $T$. carbonaria, a mais estudada. Sabe-se que esses tipos de marcadores podem ser cruciais para o monitoramento de colônias de abelhas, verificando, por exemplo, o grau de poligenia, ou mesmo a produção de machos diploide, sendo esse último um dos principais indicativos de endogamia severa ocorrendo na população (Alves et al., 2011; Francini et al., 2012).

\section{Considerações sobre o Sequenciamento de Nova Geração para o isolamento e desenvolvimento de marcadores}

O custo para o isolamento e desenvolvimento de marcadores microssatélites específicos, o torna inacessível para alguns laboratórios, pois para a montagem da biblioteca genômica e posterior isolamento dos marcadores há a necessidade da utilização de equipamentos e reagentes de preços elevados (Zane et al., 2002).

Dessa forma, diferentes estratégias vêm sendo aplicadas no intuito de superar essa barreira. Recentemente, com o advento das novas tecnologias de sequenciamento, mais precisamente o Sequenciamento de Nova Geração (Next-Generation Sequencing), a longo prazo, a identificação e obtenção de grande quantidade de marcadores está se tornando cada vez mais simples, exigindo menos tempo e baixo custo no processo. Não há a necessidade do uso de clones bacterianos, mas apenas a clonagem in vitro em sistemas de suporte sólido ou liquido, de forma a fazer milhares de leituras ao mesmo tempo (Goodwin et al., 2016).

Das até então criadas, vale destacar a plataforma Illumina Miseq que demonstrou ser útil para o desenvolvimento de marcadores microssatélites em abelhas-sem-ferrão, mas precisamente para as espécies Trigona spinipes e Melipona subnitida. Em T. spinipes foram obtidos 36 loci, sendo que 16 demonstraram altamente polimórficos, validados para verificar a capacidade adaptativa da espécie em paisagens alteradas (Jaffé et al., 2016). Em M. subnitida, os autores obtiveram um total de 23 loci sendo 
17 polimórficos, com capacidade de fazer inferências à variabilidade genética e distinção entre populações (Souza et al., 2014).

De todos os 17 conjuntos de microssatélites desenvolvidos, com exceção dos estudos desenvolvidos por Souza et al. (2014) e Jaffé et al. (2016), os demais empregaram as técnicas tradicionais de desenvolvimento, com distinção, em alguns, no processo de enriquecimento da biblioteca genômica.

Apesar da ausência da região controle, apenas duas espécies de abelhas-sem-ferrão possuem o genoma mitocondrial sequenciado, que inclui as espécies Melipona scutellaris (número de acesso do Genbank: NC_026198.1) e M. bicolor (número de acesso do Genbank: NC_004529). Dessa forma tornase necessário a obtenção de mais mitogenomas sequenciados de abelhas-sem-ferrão, não só para se desenvolver mais marcadores, como com o propósito de esclarecer com maior precisão a relação evolutiva entre as espécies (Branstetter et al., 2017).

Com a capacidade de se realizar o sequenciamento de milhares de fragmentos simultaneamente dentro de um curto período de tempo, quando comparado com o método Sanger, o sequenciamento de Nova Geração torna essa possibilidade mais clara. Além disso, essa técnica tende não só a facilitar os estudos de filogenômica, como também, contornar as limitações analíticas quando se utiliza, apenas um gene.

A desvantagem de se usar um único gene mitocondrial nas inferências filogenéticas, em abelhassem-ferrão, é a possibilidade do sequenciamento de NUMTS, cópias nucleares de genes de origem mitocondrial, transferidos durante o processo evolutivo (Zhang \& Hewitt, 1996; Cristiano et al., 2012; Ruiz et al., 2013). Sua presença pode comprometer os resultados, uma vez que sequências funcionais e não funcionais se comportam evolutivamente de forma diferente.

Para que a avaliação seja eficaz em abelhas-sem-ferrão, uma estratégia adotada é o uso de múltiplos genes concatenados, ou mesmo de mitogenomas completos para as inferências filogenéticas, sendo que estudos demonstram melhor resolução filogenética comparado àqueles que empregam um único gene (Rasmussen \& Cameron, 2010; Ramirez et al., 2010).

\section{Considerações sobre uso marcadores microssatélites heteroespecíficos em abelhas-sem-ferrão}

A preferência pelos marcadores microssatélites observados no presente estudo de revisão se dar pelo fato de disponibilizarem um grande volume de informações, principalmente pelo fato de serem marcadores codominantes, apresentar herança Mendeliana, serem, em sua maioria, seletivamente neutro, multialélico e altamente polimórfico. Basicamente são pequenas repetições em tandem com dois a seis nucleotídeos que se distribuem em todo o genoma nuclear, porém com pequena porcentagem nos genomas extranucleares (Silva et al., 2014a).

Essas características tornam indispensáveis, principalmente para compreensão de situações biológicas e ecológicas complexas como as que ocorrem com as abelhas-sem-ferrão, auxiliando dessa forma na tomada de decisão referente à conservação e melhoramento genético, principalmente daquelas populações mais frágeis às condições de manejo e adaptação. Porém, o custo ainda se torna elevado para a realidade de muitos laboratórios, como os localizados nos países da região Neotropical e do continente Africano.

Assim, para diminuir os custos com o desenvolvimento de marcadores microssatélites, baseado na propriedade de alguns sítios que flanqueiam os loci se manterem conservados entre espécies próximas evolutivamente, uma estratégia bastante útil que vem sendo adotada por diversos pesquisadores que trabalham com abelhas-sem-ferrão, é o uso de marcadores heteroespecíficos. Este vem sendo o principal impulsionador para o amplo volume de publicações relacionadas a estudos genéticos. Porém, é preciso selecionar adequadamente os marcadores que serão empregados, uma vez que a amplificação cruzada tende a diminuir não só o grau de polimorfismo, como falsear resultados referentes à diversidade genética e diferenciação populacional, gerado em consequência do aumento do número de alelos nulos, comum entre espécies mais distantes (Silva et al., 2014a).

Para superar os problemas expostos acima, softwares específicos como o Microchecker "(Van Oosterhout, 2004) e FreeNa (Chapuis \& Estoup, 2007) tendem a facilitar o processo de seleção de 
marcadores, uma vez que possuem aparato estatísticos com capacidade de identificar os loci com indícios de alelos nulos.

Em busca de marcadores úteis para estudos populacionais com abelhas-sem-ferrão foi realizado levantamento de primers heterólogos de 18 loci microssatélites que mais tiveram êxito nas pesquisas com abelhas-sem-ferrão (Tabela 3). Dos artigos disponíveis no banco de dados da WOS, os marcadores desenvolvidos para $M$. bicolor foram os que mais se destacaram nos estudos, sendo utilizados nas mais diferentes espécies, com destaque para as abelhas dos gêneros Melipona, Scaptotrigona, Plebeia e Partamona (Tabela 3). A transferência de marcadores foi mais efetiva entre espécies mais próximas evolutivamente (Viana et al., 2015; Hurtado-Burillo et al., 2016). Apesar da distância evolutiva, o marcador B124, desenvolvido para Bombus terrestres, teve bastante êxito em Scaptotrigona mexicana, tendo demonstrado alto número de alelos em algumas das populações analisadas (Hurtado-Burillo et al., 2016).

Tabela 3. Relação dos marcadores heteroespecíficos e número de espécies de abelhas-sem-ferrão que empregaram esses marcadores com os respectivos gêneros abordados.

\begin{tabular}{|c|c|c|c|}
\hline & Referência & $\begin{array}{l}\mathbf{N}^{\circ} \text { espécies } \\
\text { estudadas }\end{array}$ & Gêneros estudados \\
\hline Mbi254 & Peters et al. (1998) & 20 & $\begin{array}{l}\text { Scaptotrigona, Melipona, Paratrigona, Plebeia, Tetragonisca, } \\
\text { Schwarziana, Partamona }\end{array}$ \\
\hline Mbi278 & Peters et al. (1998) & 16 & $\begin{array}{l}\text { Austroplebeia, Paratrigona, Melipona, Scaptotrigona; Tetragonisca, } \\
\text { Plebeia, Schwarziana, Partamona, }\end{array}$ \\
\hline Mbi259 & Peters et al. (1998) & 14 & $\begin{array}{l}\text { Paratrigona, Scaptotrigona, Plebeia, Melipona, Tetragonisca; } \\
\text { Austroplebeia, Schwarziana, Partamona }\end{array}$ \\
\hline Mbi201 & Peters et al. (1998) & 12 & Melipona, Scaptotrigona, Plebeia, Tetragonisca, Partamona \\
\hline Mbi215 & Peters et al. (1998) & 11 & Plebeia, Melipona, Scaptotrigona, Tetragonisca, Schwarziana, Partamona \\
\hline Mbi218 & Peters et al. (1998) & 10 & Plebeia, Melipona, Scaptotrigona, Tetragonisca, Partamona \\
\hline Mbi232 & Peters et al. (1998) & 9 & Melipona, Paratrigona, Plebeia, Tetragonisca, Schwarziana \\
\hline Mbi28 & Peters et al. (1998) & 9 & Plebeia, Melipona, Scaptotrigona, Tetragonisca, Partamona, Tetragonula \\
\hline T4-171 & Paxton et al. (1999) & 11 & Trigona, Scaptotrigona, Melipona, Plebeia, Tetragonisca, Tegtragonula \\
\hline Mbi32 & Peters et al. (1998) & 9 & Plebeia, Melipona, Scaptotrigona, Tetragonisca, Partamona \\
\hline Mbi33 & Peters et al. (1998) & 8 & Plebeia, Partamona, Melipona, Scaptotrigona, Tetragonisca \\
\hline Mbi522 & Peters et al. (1998) & 7 & Plebeia, Melipona, Scaptotrigona, Tetragonisca, Tetragonula \\
\hline B124 & Peters et al. (1998) & 6 & Scaptotrigona, Melipona, Trigona \\
\hline Mbi233 & Peters et al. (1998) & 6 & Melipona, Paratrigona, Plebeia \\
\hline $\mathrm{T} 7-5$ & Paxton et al. (1999) & 6 & Scaptotrigona, Melipona, Trigona \\
\hline Mbi11 & Peters et al. (1998) & 5 & Melipona, Scaptotrigona, Plebeia, Partamona \\
\hline Tc4-287 & Green et al. (2001) & 4 & Trigona, Melipona, Scaptotrigona \\
\hline T8-40 & Paxton et al. (1999) & 3 & Scaptotrigona, Plebeia, Schwarziana \\
\hline
\end{tabular}

\section{Considerações finais}

Com o presente estudo de revisão realizado a partir de informações fornecidas na base de dados da Web of Science pôde-se constatar o interesse dos pesquisadores de todo o mundo pelas abelhas-semferrão, principalmente na região Neotropical, no qual o Brasil desponta com o maior número de publicações, com prevalência de estudos voltados à espécie $M$. quadrifasciata, T. angustula e $M$. scutellaris. No geral, destacou-se várias pesquisas referentes à caracterização das espécies, provavelmente devido à necessidade de maior conhecimento para o delineamento de formas mais adequadas de gestão desse recurso que é de extrema importância para a polinização da vegetação silvestre e cultivada. Com esse intuito, Brasil, México e Austrália têm utilizado os marcadores moleculares, principalmente os microssatélite e aqueles de origem mitocondrial (16S rRNA, Cox-I e Cyt-b). Porém, observou-se, no geral, limitações financeiras para a disseminação dessas ferramentas, principalmente nos países emergentes e em desenvolvimento. Apesar disso, para sanar esses problemas alguns países têm utilizado diferentes estratégias, com destaque para o uso de marcadores 
heteroespecíficos entre espécies, sendo que contribuiu bastante para alavancar as pesquisas, em função do baixo custo envolvido.

\section{Agradecimentos}

Os autores são gratos ao "Meliponicultor" Luís Pedro pela colaboração aos estudos realizados por essa equipe. Pelo financiamento disponibilizado pela Embrapa Meio-Norte (MP 06.14.01.001.00.00). Pela bolsa de estudo disponibilizada pela Coordenação de Aperfeiçoamento Pessoal de Nível Superior - Brasil (CAPES).

\section{Referências bibliográficas}

Alves, D. A., Menezes, C., Imperatriz-Fonseca, V. L. \& Wenseleers, T. 2011. First Discovery of a rare polygyne colony in the stingless bee Melipona quadrifasciata (Apidae, Meliponini). Apidologie, 42: 211-213.

Ayala, R . 1999. Revision de las abejas sin aguijon de Mexico (Hymenoptera: Apidae: Meliponini). Folia Entomológica Mexicana, 123(106): 1-123.

Ayala, R., Gonzalez, V. H. \& Engel, M. S. 2013. Mexican stingless bees (Hymenoptera: Apidae): Diversity, distribution, and indigenous knowledge. In: Vit, P., Pedro, S. R. M. \& Roubik, D. W. (Eds.). Pot-Honey: A Legacy of Stingless Bees. 1nd ed. New York: Springer-Verlag, 135-152.

Bartelli, B. F. \& Nogueira-Ferreira, F. H. 2014. Pollination services provided by Melipona quadrifasciata Lepeletier (Hymenoptera: Meliponini) in greenhouses with Solanum lycopersicum L. (Solanaceae). Sociobiology, 61(4): 510-516.

Bartelli, B. F., Santos, A. O. \& Nogueira-Ferreira, F. H. 2014. Colony performance of of Melipona quadrifasciata (Hymenoptera, Meliponini) in a greenhouse of Lycopersicon esculentum (Solanaceae). Sociobiology, 61(1): 60-67.

Borsato, D. M., Esmerino, L. A., Farago, P. V., Miguel. M. D. \& Miguel, O. G. 2013. Atividade antimicrobiana de méis produzidos por meliponíneos nativos do Paraná (Brasil). Boletim Centro de Pesquisa de Processamento de Alimentos, 31(1): 57-66.

Branstetter, M. G., Danforth, B. N., Pitts, J. P., Gates, M. W., Kula, R. R. \& Brady, S. G. 2017 Phylogenomic insights into the evolution of stinging wasps and the origins of ants and bees. Current Biology, 27(7): 1019-1025.

Brito, R. M., Francisco, F. O., Domingues-Yamada, A. M. T., Gonçalves, P. H. P., Pioker, F. C., Soares, A. E. E. \& Arias, M. C. 2009 Characterization of microsatellite loci of Tetragonisca angustula (Hymenoptera, Apidae, Meliponini). Conservation Genetics Resources, 1(1): 183-187.

Cámara, J. Q., Sousa, A. H. S., Vasconcelos, W. E., Freitas, R. S., Maia, P. H. S., Almeida, J. C. \& Maracajá, P. B. 2004. Estudos de meliponíneos, com ênfase a Melipona subnitida D. no município de Jandaíra, RN. Revista de Biologia e Ciências da Terra, 4(1): 20.

Chapuis, M. P. \& Estoup, A. 2007. "Microsatellite null alleles and estimation of population differentiation." Molecular Biology Evolution, 24(3): 621-631.

Crewe, R. M. \& Fletcher, D. J. C. 1976. Volatile secretions of two old world stingless bees. South African Journal of Science, 72: 119-120.

Cristiano, M. P., Fernandes-Salomão, T. M. \& Yotoko, K. S. C. 2012. Nuclear mitochondrial DNA: An Achilles' heel of molecular systematics, phylogenetics, and phylogeographic studies of stingless bees. Apidologie, 43(5): 527-538.

Cruz, D. O., Jorge, D. M. M., Pereira, J. O. P., Soares, C. E. A., Freitas, B. M. \& Grangeiro, T. B. 2006. Intraspecific variation in the first internal transcribed spacer (ITS1) of the nuclear ribossomal DNA in Melipona subnitida (Hymenoptera, Apidae), na endemic stingles bee from northeastern Brasil. Apidologie, 37: 376-386.

Duarte, O. M. P., Gaiotto, F., Souza, A., Mori, G. \& Costa, M. 2012. Isolation and characterization of microsatellites from Scaptotrigona xanthotricha (Apidae, Meliponini): A stingless bee in the Brazilian Atlantic rainforest. Apidologie, 43(4): 432-435. 
Egoh, B. N.O'Farrell, P. J., Charef, A., Gurney, L. J., Koellner, T., ABI, H. N., Egoh, M. \& Willemen, L. 2012. An African account of ecosystem service provision: Use, threats and policy options for sustainable livelihoods. Ecosystem Services, 2: 71-81.

Estoup, A., Solignac, M. \& Cornuet, J-M. 1994 Precise assessment of the number of patrilines and ofgenetic relatedness in honeybee colonies. Proceedings of the Royal Society B: Biological Sciences, 264:. 1-7.

Ferreira, M. N., Ballester, W. C., Dorval, A. \& Costa, R. B. 2010. Conhecimento tradicional dos Kaiabi sobre abelhas sem ferrão no Parque Indígena do Xingu, Mato Grosso, Brasil. Tellus, 10(19): 129144.

Francini, I. B., Sforça, D. A., Sousa, A. C. B., Campos, T., Cidade, F. W., Zucchi, M. I., Souza, A. P., Nunes-Silva, C. G. \& Carvalho-Zilse, G. A. 2009. Microsatellite loci for an endemic stingless bee Melipona seminigra merrillae (Apidae, Meliponini) from Amazon. Conservation Genetics Resources, 1(1): 487-490.

Francini, I. B., Sousa, A. C. B., Sforça, D. A., Costa-Pinto, M. F. F., Campos, T., Nunes-Silva, C. G., Zucchi, M. I., Souza, A. P. \& Carvalho-Zilse, G. A. 2010. Isolation and characterization of microsatellite loci in the stingless bee Melipona interrupta manaosensis (Apidae: Meliponini). Conservation Genetics Resources, 2(1): 27-30.

Francini, I. B., Nunes-Silva, C. G. \& Carvalho-Zilse, G. A. 2012. Diploid male production of two amazonian Melipona (Hymenoptera: Apidae). Hindawi, 1-7.

Francisco, F. O., Brito, R. M., Santiago, L. R., Gonçalves, P. H. P., Pioker, F. C., Domingues-Yamada, A. M. T. \& Arias, M. C. 2011. Isolation and characterization of 15 microsatellite loci in the stingless bee Plebeia remota (Apidae: Meliponini). Conservation Genetics Resources, 3(3): 417-419.

Franscisco, F. O., Domingues-Yamada, A. M. T., Gonçalves, P. H. P., Brito, R. M., Pioker, F.C., Mateus, S. \& Arias, M. C. 2013. Characterization of microsatellite loci for the stingless bee Scaura latitarsis (Hymenoptera , Apidae, Meliponini). Journal of Hymenoptera Research, 30: 7-11.

Gemim, B. S., Alcivania, F. \& Silva, D. M. 2017. Meliponicultura em sistemas agroflorestais: alternativa de renda , diversificação agrícola e serviços ecossistêmicos. Revista Agro@mbiente Online, 11(4): 361-372.

Gemmill-Herren, B., Aidoo, K., Kwapong, P., Martins, D., Wanja, K., Gikungu, M. \& Eardley, C. 2014. Priorities for research and development in the management of pollination services for agriculture in africa. Journal of Pollination Ecology, 12(1): 40-51.

Giannini, T. C., Boff, S., Cordeiro, G. D., Cartolano, E. A., Veiga, A. K., Imperatriz-Fonseca, V. L., Saraiva, A. M. 2012. Pollination services at risk: Bee habitats will decrease owing to climate change in Brazil. Ecological Modelling, 244: 127-131.

Gonçalves, L. S., Jong, D. \& Gramacho, K. P. 2010. A expansão da apicultura e da tecnologia apicola no Nordeste brasileiro, com especial destaque para o Rio Grande do Norte. Mensagem doce, 3:7-15.

Gonzalez, V. H., Griswold, T. \& Engel, M. S. 2013. Obtaining a better taxonomic understanding of native bees: Where do we start? Systematic Entomology, 38(4): 645-653.

Goodwin, S., McPherson, J. D. \& McCombie, W. R. 2016. Coming of age: ten years of NextGeneration sequencing technologies. Nature Publishing Group, 17(6): 333-351.

Green, C., Franck, P. \& Oldroyd, B. 2001. Characterization of microsatellite loci for Trigona carbonaria, a stingless bee endemic to Australia. Molecular Ecology Notes, 1(2001): 89-92.

Heard, T. A. 1994. Behavior and Pollinator Efficiency of Stingless Bees and Honey-Bees on Macadamia Flowers. Journal of Apicultural Research, 33(4): 191-198.

Heard, T. A. \& Exley, E. M. 1994. Diversity, abundance, and distribution of insect visitors to macadamia flowers. Environmental Entomology, 23(1): 91-100.

Hurtado-Burillo, M., Jara, L., May-Itza, W. J., Quezada-Euán, J. J. G., Ruiz, C. \& Rúa, P. 2016. A geometric morphometric and microsatellite analyses of Scaptotrigona mexicana and S. pectoralis (Apidae: Meliponini) sheds light on the biodiversity of Mesoamerican stingless bees. Journal of Insect Conservation, 20(5): 753-763. 
Jaffé, R., Pope, N., CostA, A. A., Alves, D. A., Arias, M. C., Rua, P., Francisco, F. O., Giannini, T.C., Gonzalez-Chaves, A., Imperatriz-Fonseca, V. L., Tavares, M. G., Jha, S. \& Carvalheiros, L. G. 2016. Landscape genetics of a tropical rescue pollinator. Conservation Genetics, 17(2): 267-278.

Jie-Ng, W. 2017. Antioxidant properties and inhibitory effects of Trigona honey against Staphylococcus aureus planktonic and biofilm cultures. International Journal of GEOMATE, 13(37): 28-33.

Keeping, M. G., Crewe, R. M. \& Field, B. I. 1982. Mandibular gland secretions of old world stingless bee, Trigona gribodoi Magretti: Isolation, identification, and compositional changes with age. Journal of Apicultural Research, 21(2): 66-73.

Kiatoko, N., Raina, S. K. \& Van Langevelde, F. 2017. Impact of habitat degradation on species diversity and nest abundance of five African stingless bee species in a tropical rainforest of Kenya. International Journal of Tropical Insect Science, 37(3): 189-197.

Korte, M., Weissenbacher, K. H. \& Crewe, R. M. 1988. Chemical signals in stingless bee Trigona (Meliplebeia) denoiti Vachal (Hymenoptera: Apidae: Meliponinae). Journal. Ent. Soc. Sth. Afr., 51(1): 9-16.

Krausa, K., Hager, F. A., Kiatoko, N. \& Kirchner, W. H. 2017. Vibrational signals of African stingless bees. Insectes Sociaux, 64(3): 415-424.

Kustiawan, P. M., Lirdprapamongkol, K., Palaga, T., Puthong, S., Phuwapraisirisan, P., Svasti, J. \& Chanchao, C. 2017. Molecular mechanism of cardol, isolated from Trigona incisa stingless bee propolis, induced apoptosis in the SW620 human colorectal cancer cell line. BMC Pharmacology and Toxicology, 18(1): 4-13.

Lopes, D. M., Silva, F. O. D., Salomao, T. M. F., Campos, L. A. D. O. \& Tavares, M. G. 2009. Microsatellite loci for the stingless bee Melipona rufiventris (Hymenoptera: Apidae). Molecular Ecology Resource, 9(3): 923-925.

Lopes, D. M., Silva, F. O., Fernandes-Salomao, T. M., Campos, L. A. O. \& Tavares, M. G. 2010. A scientific note on the characterization of microsatellite loci for Melipona mondury (Hymenoptera: Apidae). Apidologie, 41(2): 138-140.

Luizzi, D., Ferreira, J. D. \& Schneider, M. B. 2016. O comércio internacional de produtos orgânicos : atuação do Brasil e de países atuantes no setor. Caderno de Administração, 24(2): 72-88.

Megan, H., Robert, S.-H. \& Anne, D. 2013. Australian stingless bees. In: Vit, P., Roubik, D. W., pedro, S. R. M. (Eds.). Pot-Honey: A Legacy of Stingless Bees. 1nd ed. New York: Springer-Verlag, p. 3572.

Melin, A., Rouget, M., Midgley, J. J. \& Donaldson, J. S. 2014. Pollination ecosystem services in South African agricultural systems. South African Journal of Science, 110(11): 1-9.

Mercês, M. D., Peralta, E. D., Uetanabaro, A. P. T. \& Lucchese, A. M. 2013. Atividade antimicrobiana de méis de cinco espécies de abelhas brasileiras sem ferrão. Ciência Rural, 43(4): 672-675.

Michener, C. D. 2007. The Bees of the World. 2nd ed. Baltimore: The Johns Hopkins University Press, $972 \mathrm{p}$.

Monck, M., Gordon, J. \& Hanslow, K. 2008. Analysis of the market for pollination services in Australia. Barton (Australia): Rural Industries Research and Development Corporation, p.60.

Moritz, R. F. A. \& Crewe, R. M. 1988. Air ventilation in nest of two African stingless bees Trigona denoiti and Trigona gribodoi. Experientia, 44: 1024-1027.

Moura, R. F., DawsoN, D. A. \& Nogueira, D. M. 2017. The use of microsatellite markers in Neotropical studies of wild birds : a literature review. Anais da Academia Brasileira de Ciências, 89(1): 145154.

Nascimento, W. M., Gomes, E. M. L., Batista, E. A. \& Freitas, R. A. 2012. Utilização de agentes polinizadores na produção de sementes de cenoura e pimenta doce em cultivo protegido. Horticultura Brasileira, 30(3): 494-498.

Nogueira-Neto, P. 1997. Vida e Criação de Abelhas Indígenas Sem Ferrão. São Paulo: Urna Edição Noguerapis, p.447. 
Nogueira, J., Ramos, J. C., Benevento, J., Fernandes-Salomao, T. M., Resende, H. C., Campos, L. A. O. \& Tavares, M. G. 2014. Conservation study of an endangered stingless bee (Melipona capixabaHymenoptera: Apidae) with restricted distribution in Brazil. Journal of Insect Conservation, 18(3): 317-326.

Nugitrangson, P., Puthong, S., Lempridee, T., Pimtong, W., Pornpakakul, S. \& Chanchao, C. 2016. In vitro and in vivo characterization of the anticancer activity of Thai stingless bee (Tetragonula laeviceps) cerumen. Experimental Biology and Medicine, 241(2): 166-176.

Oliveira, E. J. F., Freitas, G. S., Fonseca, A. S., Souza, A. C. B., Campos, T., Assis, A. F., Souza, A. P., Contel, E. P. B. \& Soares, A. E. E. 2009. Isolation and characterization of microsatellite markers from the stingless bee Nannotrigona testaceicornis. Conservation Genetics Resources, 1-3.

Patwardhan, A., Ray, S. \& Roy, A. 2014. Molecular markers in phylogenetic studies-a review. Journal of Phylogenetics \& Evolutionary Biology, 02(02): 1-9.

Paxton, R. J., Weibschuh, N. \& Quezada-Euán, J. J. G. 1999. Characterization of dinucleotide microsatellites loci form stingless bees. Molecular Ecology, 8: 690-691.

Persson, O., Danell, R., Schneider, J. W. 2009. How to use Bibexcel for various types of bibliometric analysis. IN: Astron, F., Danell, R., Larsen, B., Schneider, J. (ORG.). celebrating scholarly communication studies: a festschrift for olle persson at his $60^{\text {th }}$ birthday, 2009, Leuven, Belgium: International Society for scientometrics and Informetrics, p. 9-24. https://homepage.univie.ac.at/juan.gorraiz/bibexcel/

Pereira, J. O. P., Freitas, B. M., Jorge, D. M. M., Torres, D. C., Soares, C. E. A. \& Granjeiro, T. B. 2009. Genetic variability in Melipona quinquefascicata (Hymenoptera, Apidae, Meliponini) from northeastern Brazil determined using the first internal transcribed spacer (ITS1). Genetics and molecular Research, 8(2): 641-648.

Peters, J. M., Queller, D. C., Imperatriz-Fonseca, V. L. \& Strassmann, j. e. 1998. Microsatellites loci stingless bees. molecular ecology, 7: 783-792.

Ramírez, S. R., Nieh, J.C., Quental, T. B., Roubik, D. W., Imperatriz-Fonseca, V. L. \& Pierce, N. E. 2010. A molecular phylogeny of the stingless bee genus Melipona (Hymenoptera: Apidae). Molecular Phylogenetics and Evolution, 56(2): 519-525.

Rasmussen, C. \& Cameron, S. A. 2010. Global stingless bee phylogeny supports ancient divergence, vicariance and long distance dispersal. Biological Journal of the Linnean Society, 99(1): 206-232.

Rúa, P., Jaffé, R., Muñoz, I., Serrano, J., Moritz, R. F. A. \& Kraus, F. B. 2007. Sequence and RFLP analysis of the ITS2 ribosomal DNA in two Neotropical social, Melipona beecheii and Melipona yucatanica (Apidae, Meliponini). Insect Sociaux, 54(4): 418-423.

Ruiz, C., May-Itzá, W. J., Quezada-Euán, J. J. G. \& Rúa, P. 2013. Presence of nuclear copies of mitochondrial origin (NUMTs) in two related species of stingless bee genus Melipona (Hymenoptera: Meliponini). Journal of Zoological Systematics and Evolutionary Research, 51(2): 107-113.

Santiago, L. R., Pioker-Hara, F. C., Francisco, F. O., Brito, R. M., Gonçalves, P. H. P., DominguesYahamda, A. M. T. \& Arias, M. C. 2015. Isolation and characterization of ten microsatellite loci in stingless bee Trigona spinipes (Apidae: Meliponini). Entomological Science, 18(1) 138-140.

Santos, C. M., Campos, J. F., Santos, H. F., Baliestirei, J. B. P., Silva, D. B., Souza, K. P., Carollo, C. A., Estevino. L. M. \& Santos, E. L. 2017. Chemical Composition and Pharmacological Effects of Geopropolis Produced by Melipona quadrifasciata anthidioides. Oxidative Medicine and Cellular Longevity, 1-13.

Silva, G. R., Pereira, F. M., Souza, B. A., Lopes, M. T. R., Campelo, J. E. G. \& Diniz, F. M. 2014a. Aspectos bioecológicos e genético-comportamentais envolvidos na conservação da abelha Jandaíra, Melipona subnitida Ducke (Apidae, Meliponini), e o uso de ferramentas moleculares nos estudos de diversidade. Arquivos do Instituto Biológico, 81(3): 299-308.

Silva, G. R., Souza, B. A., Pereira, F. M., Lopes, M. T. R., Valente, S. E. S., Diniz, F. M. 2014b. New molecular evidence for fragmentation between two distant populations of the threatened stingless 
bee Melipona subnitida Ducke (Hymentoptera, Apidae, Meliponini). Journal of Hymenoptera Research, 38: 1-9.

Silva, M. D. E, Ramalho, M. \& Rosa, J. F. 2011. Por que Melipona scutellaris (Hymenoptera, Apidae) forrageia sob alta umidade relativa do ar? Iheringia. Série Zoologia, 101(1-2): 131-137.

Silveira, F. A., Melo, G. A. R., Almeida, E. A. B. 2002. Abelhas brasileiras, Sistemática e Identificação. Belo Horizonte, Fernando A. Silveira, p.253.

Slaa, e. J., Chaves, L. A. S., Malagodi-Braga, K. S. \& Hofstede, F. E. 2006. Stingless bees in applied pollination : practice and perspectives. Apidologie, 37(2): 293-315.

Souza, I. G. B., Paterson, I., McBride, M. C., Souza, B. A., Pereira, F. M. Lopes, M. T. R., Bentzen, P., Diniz, F. M. 2014. Isolation and characterization of 23 microsatellite loci in the stingless bee Melipona subnitida using Next-Generation sequencing. Conservation Genetics Resources, 7-9.

Tavares, M. G., Pietrani, N.T., Durvale, M. C., Resende, H. C. \& Campos, L. A. O. 2013a. Genetic divergence between Melipona quadrifasciata Lepeletier (Hymenoptera, Apidae) populations. Genetics and Molecular Biology, 36 (1):111-117.

Tavares, M. G., Almeida, B. S., Passamani. P. Z., Paiva, S. R., Resende, H. C., Campos, L. A. O., Alves, R. M. O. \& Waldschmidt, A. M. 2013b. Genetic variability and population structure in Melipona scutellaris (Hymenoptera: Apidae) from Bahia, Brazil, based on molecular markers. Apidologie, 44: $720-728$.

Thummajitsakul, S., Klinbunga, S. \& Sittipraneed, S. 2010. Development of a species-diagnostic marker for identification of the stingless bee Trigona pagdeni in Thailand. Biochemical Genetics, 48(3-4): 181-192.

Torres-Ruiz, A., Jones, W. R. \& Barajas, R. A. 2013. Present and potential use of bees as managed pollinators in Mexico. Southwestern Entomologist Perspective, 38(1): 133-147.

Van Oosterhout, C., Hutchinson, W.F., Wills, D.P.M. \& Shipley, P. 2004. "MICROCHECKER: Software for identifying and correcting genotyping errors in microsatellite data." Molecular Ecology Notes, 4(3): 535-538.

Venturieri, G. C. 2008. Criação de abelhas Indígenas sem Ferrão. 2nd ed. Belém, Pará: Embrapa Amazônia Oriental, 26 p.

Viana, M. V. C., Carvalho, C. A. L., Sousa, H. A. C., Francisco, A. K. \& Waldschmidt, A. M. 2015. Mating frequency and maternity of males in Melipona mondury (Hymenoptera: Apidae). Insectes Sociaux, 62(4): 491-495.

Yang, W., Kang, X., Yang, Q., Lin, Y. \& Fang, M. 2013. Review on the development of genotyping methods for assessing farm animal diversity. Journal Anim Sci Biotechnol, 4: 2.

Zane, L., Bargelloni, L. \& Patarnello, T. 2002. Strategies for microsatellite isoloation: a review. Molecular Ecology, 11(1): 1-16.

Zhang, D., Hewitt, G. M. 1996. Nuclear integrations: challenges for mitochondrial DNA markers. Science, 11(96): 247-251.

Recebido: 16 novembro, 2018

Aprovado: 4 dezembro, 2018.

Publicado: 21 janeiro, 2019.

Licenciamento: Este artigo é publicado na modalidade Acesso Aberto sob a licença Creative Commons Atribuição 4.0 (CC-BY 4.0), a qual permite uso irrestrito, distribuição, reprodução em qualquer meio, desde que o autor e a fonte sejam devidamente creditados. 